\title{
The Advancements in Mastitis Therapy
}

\author{
Rinku Buragohain and Tapas Kumar Sar* \\ Department of Veterinary Pharmacology and Toxicology, West Bengal University of Animal and Fishery Sciences 37, India
}

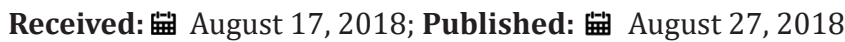

*Corresponding author: Tapas Kumar Sar, Department of Veterinary Pharmacology and Toxicology, West Bengal University of Animal and Fishery Sciences 37, K.B. Sarani, Kolkata-700037, West Bengal, India

Abbreviations: FBD: Food Borne Diseases; SFD: Staphylococcal Food Borne Disease; SEs: Staphylococcal Enterotoxins; MIC: Minimum Inhibitory Concentration; AMR: Antimicrobial Resistance

\section{Opinion}

There are over 264 million dairy cows worldwide, producing nearly 600 million tonnes of milk every year. The global average for milk production is approximately 2,200 litres per cow (FAOstat 2012). Around $12.5 \%$ of world's cattle population is present in India with a total cow population of 122.9 million and out of which 19.42 million is exotic/crossbred milch cattle (Livestock census, 2007). As per reports of occurrence of mastitis in dairy animals, it stands at first position because prevalence of mastitis had been reported more than $90 \%$ in high yielder crossbred dairy cows [1]. Mastitis is an inflammatory condition of the mammary gland irrespective of causes. It is characterized by physical, chemical, and microbiological changes in the milk and pathological changes in glandular tissues of the mammary gland. According to their epidemiology, mastitis pathogens can be divided into contagious and environmental. The primary reservoir of contagious pathogens is an infected udder whereas a contaminated environment is the primary reservoir of pathogens causing environmental mastitis [2].

Streptococcus agalactiae, Staphylococcus aureus and Mycoplasma spp. are considered as typical contagious pathogens. Typical environmental pathogens are so-called environmental streptococci (Streptococci other than $S$. agalactiae such as Streptococcus uberis; enterococci), Enterobacteriaceae and coagulase-negative staphylococci [3]. The leading organism is Staphylococcus aureus, producing acute suppurative, gangrenous, or chronic mastitis depending on the infecting strains. Generally, mastitis can appear in two forms i.e., clinical or overt and subclinical or hidden [4]. Sub-clinical mastitis is $15-40$ times more prevalent than clinical mastitis and causes high economic losses in most dairy herds. S. aureus is a significant cause of food borne diseases (FBD), causing an estimated 241,000 illnesses per year in the United States [5] FBD impose a great economic burden, accounting for $\$ 50-\$ 80$ billion annually in "health care costs, lost productivity, and diminished quality of life" in the United States $[6,7]$. It is estimated that each case of Staphylococcal food borne disease (SFD) costs $\$ 695$, representing a total cost of $\$ 167,597,860$ annually in the United States [6]. S. aureus produces wide arrays of toxins. Staphylococcal enterotoxins (SEs) are a family of nine major serological types of heat stable enterotoxins (SEA, SEB, SEC, SED, SEE, SEG, SEH, SEI, and SEJ) that belong to the large family of pyrogenic toxin superantigens $[8,9]$. Pyrogenic toxins cause immune suppression and nonspecific T-cell proliferation [10].

S. aureus is often implicated with caprine mastitis [11]. In sheep, goats, and cattle, SEC was the predominant toxin type detected in $S$. aureus isolated from mastitis milk [12]. Other studies have documented SEC producers as the most prevalent enterotoxin producing $S$. aureus isolated from goat's milk [13] and goat's skin of udder, teats, and milk [14]. Six SFD outbreaks in France in 2009 were caused by SEE present in soft cheese made from unpasteurized milk [15]. Considering the economic and public health importance in the global scenario, some therapeutic strategies have been developed by our team for treatment of mastitis in an ethical manner. Antibiotic therapy is a common practice in mastitis and the efficacy can be maximized by keeping the drug concentration at the site of infection above the minimum inhibitory concentration (MIC) as long as possible [16,17]. Although antibiotics are useful to treat the bacterial infection, they cannot protect the glands from tissue damage.

Repeated administration of antimicrobial agent is also required to maintain MIC for an adequate period to cure mastitis which is not cost effective. Besides, the animals sometime suffer from systemic infection due to the spread of the microorganism from the infected mammary gland. Though intramammary administration is also adopted for treatment of mastitis but, intramammary administraton of most of the antibiotics was suspected to cause mammary gland tissue damage. An excess of reactive oxygen species and the absence of optimal amounts of antioxidants lead to oxidative stress. Many cells are susceptible to this oxidative stress, which can cause necrosis or apoptosis. Keeping these factors 
into consideration, some supportive herbal therapies were used as adjunct to single antibiotic agent to protect the animal from oxidative stress, inflammation and related patho physiological changes.

It was found that $O$. sanctum leaf juice having potent bioavailability enhancing and antioxidant properties can be considered as a supportive therapy to intravenous ceftriaxone injection in staphylococcal chronic mastitis in goat [18]. Histomorphological evaluation exhibited marked a reduction of the fibrous tissue in the left half and more number of active columnar epithelial cells in the right half of the udder in mastitic animals in our previous study, which indicated anti fibrotic activity of $B$. variegata L. bark powder. B. variegata L., having bioenhancing, antibacterial, anti inflammatory, antioxidant and anti fibrotic properties was found to be an effective adjunct therapy with antibiotic treatment in chronic mastitis [19]. Generally, broad spectrum antibiotics are used for treatment of mastitis as it is often caused by multiple number of organisms. But, use of more than one antibiotic that too after repeated dosing may result in longer persistence of antibiotic residues in milk/mammary gland causing development of antimicrobial resistance and other pathological complexities. A broad-spectrum antibiotic i.e. ceftriaxone was found to be effective in mastitis following single dose intravenous administration in cows and goats $[20,21]$.

Another antibiotic having structural similarity with ceftriaxone i.e. ceftizoxime was also effective in treatment of mastitis of buffaloes [22]. Therefore, herbal therapies like herbal extract of Oscimum sanctum and bark powder of Bauhinia variegata were recommended as supportive therapies with single dose of intravenous ceftriaxone/ceftizoxime in mastitis in cows, buffaloes and goats. When cattle are given antibiotics to treat mastitis, their milk retains the antibiotics for a long time, increasing the probability of antimicrobial resistance (AMR). It was reported that a commercially available mammary protective polyherbal drug (Fibrosin $®$ ) [23] when given alongside the antibiotics, can prevent antimicrobial resistance. As mastitis leads to reduced milk yield in goats, cows and buffaloes. It is not only a major concern for the dairy industry but also a public health menace.

Ceftriaxone used to treat affected cattle gets converted in their liver into an active metabolite called ceftizoxime, another thirdgeneration cephalosporin excreted in their milk for a prolonged period following treatment. It was suggested that the polyherbal drug not only increased the bioavailability of ceftizoxime in milk, but also helped to eliminate it much faster than in a control group of goats that did not receive Fibrosin $®$. Since persistence of antibiotics for a prolonged period in milk triggers antimicrobial resistance (AMR), the polyherbal drug could be used as a supportive therapy to treat sensitive bacterial infections in cattle to minimise development of AMR [24]. Therefore, our recommended herbal supportive therapies should be applied in milk producing animals towards production of safe milk as it is consumed by a large population in the world.

\section{References}

1. Sharma N (2003) Epidemiological investigation on sub clinical mastitis in dairy animals: Role of Vitamin E and Selenium supplementation on its control in cattle. M.V.Sc. Thesis, Submitted to I.G.K.V.V, Raipur, Chhattisgarh, India.

2. Hillerton JE, Berry EA (2005) Treating mastitis in the cow-a tradition or an archaism. J Appl Microbiol 98(6): 1250-1255.

3. Kluytmans J, Van Belkum A, Verbrugh H (1997) Nasal carriage of Staphylococcus aureus: epidemiology, underlying mechanisms, and associated risks. Clin Microbiol Rev 10(3): 505-520.

4. Radostits OM, Gay C, Blood DC, Hinchcliff K, Constabl P (2000) Mastits Veterinary Medicine: A Text book of disease of cattle, sheep, pigs, goats, and horses ( $9^{\text {th }}$ edn.), Ballier, Tindall, and London: W.B. Saunders Company Ltd. Pp. 674-762.

5. Scallan E, Hoekstra RM, Angulo FJ, Tauxe RV, Widdowson MA, et al. (2011) Food borne illness acquired in the United States-major pathogens. Emerg Infect Dis 17(1): 7-15.

6. Byrd-Bredbenner C, Berning J, Martin-Biggers J, Quick V (2013) Food safety in home kitchens: a synthesis of the literature. Int J Environ Res Public Health 10(9): 4060-4085.

7. Scharff RL (2012) Economic burden from health losses due to food borne illness in the United States. J Food Prot 75 (1): 123-131.

8. Balaban N, Rasooly A (2000) Staphylococcal enterotoxins. Int J Food Microbiol 61(1): 1-10.

9. Argudín MA, Mendoza MC, Rodicio MR (2010) Food poisoning and Staphylococcus aureusenterotoxins. Toxins 2(7): 1751-1773.

10. Le Loir Y, Baron F, Gautier M (2003) Staphylococcus aureus and food poisoning. Genet Mol Res 2(1): 63-76.

11. De Buyser ML, Dilasser F, Hummel R, Bergdoll MS (1987) Enterotoxin and toxic shock syndrome toxin-1 production by staphylococci isolated from goat's milk. Int J Food Microbiol 5(4): 301-309.

12. Scherrer D, Corti S, Muehlherr JE, Zweifel C, Stephan R (2004) Phenotypic and genotypic characteristics of Staphylococcus aureus isolates from raw bulk-tank milk samples of goats and sheep. Vet Microbiol 101(2): 101-107.

13. Foschino R, Invernizzi A, Barucco R, Stradiotto K (2002) Microbial composition including the incidence of pathogens, of goat milk from the Bergamo region of Italy during a lactation year. J Dairy Res 69(2): 213225 .

14. Valle J, Gomez-Lucia E, Piriz S, Goyache J, Orden JA, et al. (1990) Enterotoxin production by staphylococci isolated from healthy goats. Appl Environ. Microbiol 56(5): 1323-1326.

15. Ostyn A, De Buyser ML, Guillier F, Groult J, Felix B, et al. (2010) First evidence of a food poisoning outbreak due to staphylococcal enterotoxin type E, France (2009) Euro Surveill 15(13) pii: 19528.

16. Sawant AA, Sordillo LM, Jayarao BM (2005) A survey on antibiotic usage in dairy herds in Pennsylvania. J Dairy Sci 88(8): 2991-2999.

17. Cagnardi P, Villa P, Gallo M, Locatelli C, Carli S, et al. (2010) Cefoperazone sodium preparation behaviour after intramammary administration in healthy and infected cows. J Dairy Sci 93(9): 4105-4110.

18. Dash JR, Sar TK, Samanta I, Mandal TK (2016) Effects of herbal extract of Ocimum sanctum as supportive therapy with intravenous ceftriaxone in experimentally induced staphylococcal chronic mastitis in goat. Small Rumin Res 137: 1-8.

19. Dash JR, Sar TK, Samanta I, Pal S, Khan M, et al. (2014) Efficacy evaluation of Bauhinia variegata L. stem bark powder as adjunct therapy in chronic Staphylococcus aureus mastitis in goat. Pharmacogn Mag 10(Suppl3): 512-518. 
20. Sar TK, Mandal TK, Das SK, Chakraborty AK, Bhattacharyya A (2006) Pharmacokinetics of ceftriaxone in healthy and mastitic goats with special reference to its interaction with polyherbal drug (fibrosinß). Int J Appl Res Vet M 4(2): 142-154.

21. Sar TK, Mandal TK, Samanta I, Rahaman A, Chakraborty AK (2010) Determination of ceftriaxone in plasma and ceftizoxime in milk of mastitic cows following single dose intravenous administration. Indian J Anim Sci 80(12): 1182-1184.

22. Kumar R, Sar TK, Patra PH, Samanta I, Mishra A, et al. (2016) Disposition kinetics of ceftizoxime in acute mastitis in Murrah buffaloes. Indian J Anim Sci 86(2): 140-142.

ISSN: 2574-1241

DOI: $10.26717 / B J S T R .2018 .08 .001646$

Tapas Kumar Sar. Biomed J Sci \& Tech Res

(C) This work is licensed under Creative

Submission Link: https://biomedres.us/submit-manuscript.php
23. Sar TK, Patra AK, Samanta I, Mandal TK (2015) Protective effect of a potential polyherbal drug on mammary tissue damage caused by intramammary administration of antibiotic by producing antioxidant action. Indian J Anim Hlth 54(1): 35-42.

24. Sar TK, Samanta I, Mahanti A, Akhtar S, Dash JR (2018) Potential of a polyherbal drug to prevent antimicrobial resistance in bacteria to antibiotics. Sci Rep 8(1): 10899.

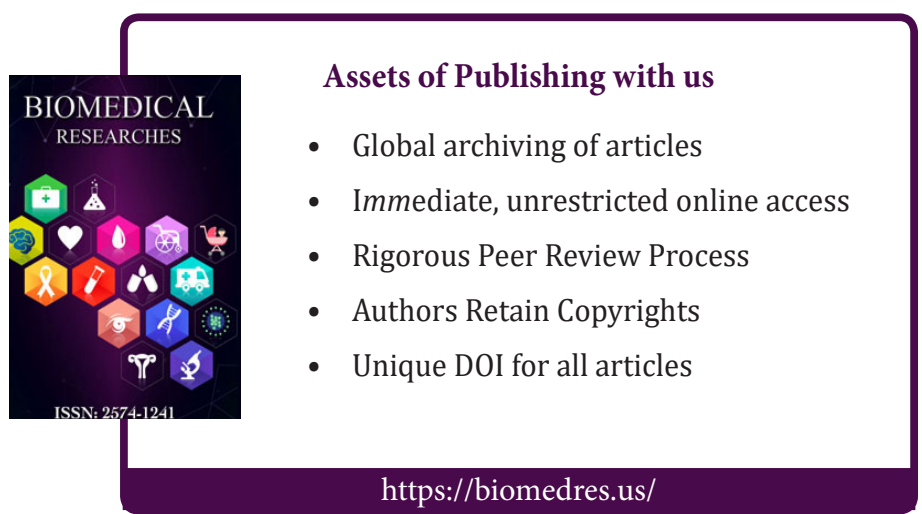

